\title{
Association between Year of Birth and Cognitive Functions in Russia and the Czech Republic: Cross-Sectional Results of the HAPIEE Study
}

\author{
Martin Bobak ${ }^{b}$ Marcus Richards ${ }^{a}$ Sofia Malyutinac Ruzena Kubinovad \\ Anne Peasey $^{\mathrm{b}}$ Hynek Pikhart $^{\mathrm{b}}$ Sergei Shishkin ${ }^{c}$ Yuri Nikitin $^{c}$ Michael Marmot $^{\mathrm{b}}$ \\ ${ }^{a}$ MRC Unit for Lifelong Health, ${ }^{b}$ Department of Epidemiology and Public Health, University College London, London, \\ UK; ' Institute of Internal Medicine, Siberian Branch of the Russian Academy of Medical Sciences, Novosibirsk, Russia; \\ ${ }^{\mathrm{d}}$ National Institute of Public Health, Prague, Czech Republic
}

\section{Key Words}

Cognitive functions · Ageing $\cdot$ Birth cohort effect $\cdot$ Eastern Europe

\begin{abstract}
Objectives: To assess differences in cognitive functions by year of birth in Russia and the Czech Republic. Methods: A cross-sectional study in the general population of Novosibirsk (Russia) and 6 cities of the Czech Republic recruited random samples of men and women (3,874 Russians, 3,626 Czechs) aged 45-69 years in 2002 (i.e. born in 1933-1957). Word recall, verbal fluency (number of animals named in $1 \mathrm{~min}$ ) and letter search were assessed in a clinic. Results: Except letter search in men, we found similar levels of cognitive functioning in Russians and Czechs in the youngest subjects and a steeper association of functioning with year of birth in Russia than in the Czech Republic. For example, the difference in the mean word recall, associated with 10 years difference in year of birth, was 0.9 (SE 0.06) words in Russian men, compared to 0.4 (0.06) words in Czech men; in women, these figures were $0.8(0.05)$ and $0.3(0.05)$, respectively. For all outcomes, except letter search in men, the interactions between year of birth and country were statistically highly significant, and the differences in the year of birth effects
\end{abstract}

between countries were largely unexplained by socioeconomic indicators and risk factors. Conclusion: The slope of association between lower cognitive functioning and earlier year of birth is much steeper in Russia than in the Czech Republic. Given that poor cognitive functioning is a risk factor for dementia, long-term follow-up of this cohort and other studies into population rates of cognitive impairment in Russia should be a priority.

Copyright $\odot 2009$ S. Karger AG, Basel

\section{Introduction}

The Russian health crisis during the societal transformation following the change from command to market economy after the demise of the USSR has attracted considerable attention [1-3]. However, research on Russian health to date has largely focused on midlife, where mortality fluctuations are most pronounced [2], and there is very little information on the health of the Russian elderly. Two studies, using different data, have shown that levels of physical health and physical functioning in the Russian population were similar to western populations until the age of about 45 years; after that, age-associated decline in health was much faster than in the west $[4,5]$.

\section{KARGER}

๑ 2009 S. Karger AG, Basel

Fax +41613061234 E-Mail karger@karger.ch www.karger.com www.karger.com/ned
Martin Bobak

Department of Epidemiology and Public Health, University College London 1-19 Torrington Place

London WC1E 6BT (UK)

Tel. +44 203108 3021, Fax +44 207813 0242, E-Mail: m.bobak@ucl.ac.uk 
These findings may reflect birth cohort effects, selective survival, age-related decline or all of these. It is interesting, however, that a similar pattern seems to hold within populations in western countries with respect to socioeconomic status (SES) and other aspects of disadvantage. In a longitudinal analysis of the UK Whitehall Study, decline in physical functioning with age was faster in lower socioeconomic groups [6]. In the United States, African-Americans - and African-American women in particular - showed a steeper age gradient in hypertension than white participants in the National Health and Nutrition Examination Survey [7]. This phenomenon is also seen in cognitive function $[8,9]$, since there are a wide range of factors that grade cognition by SES, from material resources that determine access to lifestyle, quality of home, neighbourhood and workplace, to health behaviours and health 'literacy', to psychosocial processes based on status that ultimately influence neural systems underlying cognition.

To our knowledge, no data on the population levels of cognitive functioning in Russia have been published so far. Given the very high levels of mortality, cardiovascular diseases, alcohol-related problems and unhealthy lifestyles in Russia [2, 10], and given the findings on physical functioning mentioned above $[4,5]$, we hypothesized that the association of cognitive functions with age (and, conversely, with year of birth) in Russia is steeper than in populations with higher income status and better levels of general health. In this study, we used the Czech Republic as a comparison to Russia. The Czech Republic, although also a former communist country, is an example of a successful societal transformation after the fall of communism, and its health indicators are now close to Western Europe. For example, in 2005, the life expectancies at age 45 years in Russia, Czech Republic and the European Union were 21.6, 30.0 and 32.5 , respectively, in men, and 31.0, 35.4 and 37.9 years, respectively, in women (WHO Health for all database, www.euro.who.int/hfadb).

\section{Methods}

\section{Study Populations and Subjects}

The data come from the HAPIEE (Health, Alcohol and Psychosocial Factors in Eastern Europe) study. Details of the study protocol have been reported elsewhere [11]. Briefly, random population samples of men and women aged 45-69 years on 1 January 2002 (i.e. born in 1933-1957) were selected in Novosibirsk (Russia), Krakow (Poland) and 6 Czech cities, and invited to participate in the study. In Russia and the Czech Republic, participants were invited for examination in a clinic, while in Poland the subjects were visited and examined in their homes. Because of this difference in methodology (which significantly affected the measurement of the main outcomes analysed here), this report is confined to the Russian and Czech samples. The response rates were $61 \%$ in Russia and 55\% in the Czech Republic. Cognitive functions were assessed in all participants who were retired and in an approximately $20 \%$ random sub-sample of working participants (different characteristics were studied in working and non-working subjects but, for comparability, cognitive functions were also measured in a sub-sample of working persons). The numbers of participants with full data were 3,874 in Russia and 3,626 in the Czech Republic.

\section{Measurements}

Three aspects of cognition - memory, verbal fluency, and speed and concentration - were assessed because these represent functions important for skilled daily living, and because they are all demanding of central processing resources and therefore vulnerable to age- or morbidity-associated decline. The memory and verbal learning test consisted of the recall of 10 words. The words were identical in each country (employing the most commonly used translation); the word list was recorded on a tape and participants had $1 \mathrm{~min}$ for the recall. There were 3 consecutive immediate recalls and 1 delayed recall; the 3 rd immediate recall was used in these analyses. Verbal fluency was examined by asking participants to name as many animals as possible within $1 \mathrm{~min}$. Speed and concentration were tested by asking participants to cross out as many target letters ('P' and 'W') as possible within $1 \mathrm{~min}$, using a sheet with random letters of the alphabet set out in rows and columns. In Russia, which uses a different alphabet, we used letters 'P' (identical as in the Latin alphabet) and ' $W$ ' (visually similar to ' $W$ ' in the Latin alphabet). Participants were asked at invitation to bring their glasses and hearing aids, and the absence of these aids, which could affect participants' performance in these tests, was noted; subjects reporting that vision/hearing problems interfered with their tests $(2.0 \%$ in Czech Republic and $1.5 \%$ in Russia) were excluded from the analyses.

In addition to cognitive function, we also included an indicator of physical functioning to assess consistency with previous data $[4,5]$. We used the 10 questions on activities of daily living from the SF36 questionnaire $[12,13]$. The examination further included measurements of blood pressure, anthropometry, lung functions and a blood sample. Participants also completed an extensive questionnaire on their health status, medical history, cardiovascular risk factors and health behaviours, economic status, socioeconomic circumstances and psychosocial factors [11]. Education was categorized into 5 groups (less than primary, primary, vocational, complete secondary, and university). A material deprivation score was based on frequency of not having enough money for food, clothing and paying bills. Physical functioning was measured by the 10 questions on activities of daily living from the SF36 questionnaire $[12,13]$. All forms, including the questionnaire and cognitive function sheets, were translated into the relevant language and back-translated to English to ensure that meanings were identical. Data collection followed a central protocol, also translated into each language. All personnel involved in data collection were centrally trained and frequent field visits to each country were made to ensure that all procedures follow the central protocol. The study was approved by the ethics committees at University College London and at each local institution. 
Table 1. Descriptive characteristics of the subjects

\begin{tabular}{|c|c|c|c|c|}
\hline & \multicolumn{2}{|l|}{ Men } & \multicolumn{2}{|l|}{ Women } \\
\hline & $\begin{array}{l}\text { Czech Rep. } \\
(\mathrm{n}=1,634)\end{array}$ & $\begin{array}{l}\text { Russia } \\
(\mathrm{n}=1,837)\end{array}$ & $\begin{array}{l}\text { Czech Rep. } \\
(\mathrm{n}=1,992)\end{array}$ & $\begin{array}{l}\text { Russia } \\
(\mathrm{n}=2,037)\end{array}$ \\
\hline Mean word recall & $8.2(1.4)$ & $7.8(1.8)$ & $8.7(1.3)$ & $8.2(1.6)$ \\
\hline Mean number of animals & $23.0(6.9)$ & $19.7(7.1)$ & $23.1(6.5)$ & $19.2(6.4)$ \\
\hline Mean number of crossed letters & $17.2(5.1)$ & $14.2(7.3)$ & $18.4(4.4)$ & $16.1(7.0)$ \\
\hline Mean physical functioning, \% of max. & $84.8(17.0)$ & $85.5(19.2)$ & $80.7(19.1)$ & $75.1(22.7)$ \\
\hline \multicolumn{2}{|l|}{ Age group (year of birth), \% } & 10.2 & 8.2 & 9.6 \\
\hline $50-54(1948-1952)$ & 8.6 & 14.0 & 9.5 & 12.4 \\
\hline $55-59(1943-1947)$ & 14.4 & 14.3 & 14.3 & 14.9 \\
\hline 60-64 (1938-1942) & 34.5 & 26.1 & 38.5 & 27.5 \\
\hline $65-69(1933-1937)$ & 36.2 & 35.5 & 29.4 & 35.7 \\
\hline \multicolumn{5}{|l|}{ Education, \% } \\
\hline Primary & 6.0 & 11.4 & 19.6 & 10.7 \\
\hline Vocational & 45.6 & 33.8 & 31.3 & 33.3 \\
\hline Secondary & 31.8 & 20.8 & 39.7 & 29.1 \\
\hline University & 16.7 & 34.0 & 9.7 & 27.1 \\
\hline Current smoking, \% & 22.7 & 44.5 & 17.7 & 6.9 \\
\hline Prevalence of binge drinking, $\%$ & 14.3 & 27.1 & 2.0 & 0.8 \\
\hline Mean annual alcohol intake (ethanol), litres & $5.8(9.5)$ & $4.9(8.5)$ & $1.3(3.1)$ & $0.4(1.3)$ \\
\hline Mean material deprivation score & $1.4(2.1)$ & $3.0(3.5)$ & $1.7(2.3)$ & $3.7(3.5)$ \\
\hline Mean systolic BP, mm Hg & $146.2(19.4)$ & $144.2(23.3)$ & $136.8(20.3)$ & $147.1(26.0)$ \\
\hline Mean body mass index & $28.6(4.0)$ & $26.7(4.4)$ & $28.8(5.0)$ & $30.3(5.5)$ \\
\hline Mean FEV 1 & $2.95(0.7)$ & $2.97(0.8)$ & $2.16(0.5)$ & $2.22(0.5)$ \\
\hline Mean leg length, $\mathrm{cm}$ & $84.4(5.0)$ & $80.5(4.4)$ & $76.7(4.3)$ & $72.8(4.2)$ \\
\hline
\end{tabular}

Data in parentheses are SD.

\section{Statistical Analyses}

As explained above, the final analyses had 4 main outcome variables: (1) the number of correct words in the 3rd immediate recall; (2) the number of animals named within $1 \mathrm{~min}$; (3) the number of correctly crossed out letters within $1 \mathrm{~min}$; (4) good physical functioning, defined as $\geq 70 \%$ of the maximum score on the physical functioning questions, which was included in order to assess whether the gradients by year of birth are similar for cognitive and physical functions.

All analyses were performed separately for men and women. For each country separately, we first tabulated each outcome against year of birth (1933-1937; 1938-1942; 1943-1947; 1948 1952; 1953-1957). The relationships between the 3 cognitive functions and year of birth were approximately linear (i.e. linear model fitted the data better than alternatives); for physical functioning, an exponential model (using year of birth squared) explained the data best and was used in the main analyses.

We then used linear regression to estimate the association between year of birth (or its square in the case of physical functioning) as the continuous variable and each outcome, with both countries included in 1 model, and we tested for the interaction between country and year of birth. The regression coefficients are expressed per 10-year decrease in year of birth. The statistical significance of the interaction was tested by the change in the likelihood ratio between models without and with the interaction term. This was done in 3 stages. First, the country differences in the unadjusted slopes between birth year and cognitive outcomes were tested, as explained above. Second, to test the hypothesis that a steeper birth year gradient in cognition in Russia would be explained by socioeconomic circumstances, these models were adjusted for education and deprivation. Third, to test the hypothesis that a steeper year of birth gradient in cognition in Russia would be explained by poorer health, the models were further adjusted for the following health indicators: systolic blood pressure, current smoking (at least 1 cigarette per day), body mass index, leg length, $\mathrm{FEV}_{1}$ (forced expiratory volume in $1 \mathrm{~s}$ ), annual alcohol consumption, and binge drinking (drinking at least $100 \mathrm{~g}$ of alcohol at least once a month). The interaction between country and birth year was re-tested after controlling for all these factors. STATA 8 (Stata Corp.) was used for all analyses.

\section{Results}

Characteristics of the participants included in this report are shown in table 1 . The smaller numbers of younger participants, compared to older age groups, are the result of the under-sampling of subjects younger than 60 
Table 2. Mean physical and cognitive functions by year of birth

\begin{tabular}{|c|c|c|c|c|c|}
\hline Year of birth & $\mathrm{n}$ & $\begin{array}{l}\text { Word } \\
\text { recall }^{\mathrm{a}}\end{array}$ & $\begin{array}{l}\text { Ani- } \\
\text { mals }\end{array}$ & $\begin{array}{l}\text { Letter } \\
\text { crossing }\end{array}$ & $\begin{array}{l}\text { Physical } \\
\text { functioning }\end{array}$ \\
\hline \multicolumn{6}{|l|}{ Czech Republic } \\
\hline \multicolumn{6}{|l|}{ Men } \\
\hline 1953-1957 & 110 & 8.8 & 25.1 & 18.7 & 92.0 \\
\hline $1948-1952$ & 140 & 8.5 & 24.1 & 18.4 & 86.6 \\
\hline $1943-1947$ & 229 & 8.3 & 23.5 & 17.8 & 85.5 \\
\hline $1938-1942$ & 563 & 8.3 & 23.2 & 17.3 & 85.8 \\
\hline $1933-1937$ & 592 & 7.9 & 21.9 & 16.3 & 81.9 \\
\hline Total & 1,634 & 8.2 & 23.0 & 17.2 & 84.8 \\
\hline \multicolumn{6}{|l|}{ Women } \\
\hline 1953-1957 & 164 & 9.2 & 25.3 & 19.0 & 88.0 \\
\hline $1948-1952$ & 190 & 9.0 & 24.8 & 19.2 & 84.2 \\
\hline $1943-1947$ & 285 & 8.8 & 23.6 & 18.4 & 82.8 \\
\hline $1938-1942$ & 767 & 8.6 & 23.0 & 18.6 & 81.0 \\
\hline 1933-1937 & 586 & 8.6 & 21.8 & 17.6 & 75.9 \\
\hline Total & 1,992 & 8.7 & 23.1 & 18.4 & 80.7 \\
\hline \multicolumn{6}{|l|}{ Russia } \\
\hline \multicolumn{6}{|l|}{ Men } \\
\hline 1953-1957 & 187 & 9.1 & 24.9 & 16.5 & 92.5 \\
\hline $1948-1952$ & 257 & 8.4 & 23.8 & 15.2 & 89.5 \\
\hline 1943-1947 & 263 & 8.3 & 22.1 & 13.9 & 89.5 \\
\hline $1938-1942$ & 480 & 7.7 & 19.9 & 14.3 & 85.9 \\
\hline 1933-1937 & 650 & 7.2 & 16.8 & 13.3 & 79.9 \\
\hline Total & 1,837 & 7.8 & 19.7 & 14.2 & 85.5 \\
\hline \multicolumn{6}{|l|}{ Women } \\
\hline 1953-1957 & 195 & 9.2 & 23.5 & 19.6 & 85.1 \\
\hline 1948-1952 & 252 & 8.9 & 23.3 & 17.2 & 82.2 \\
\hline $1943-1947$ & 303 & 8.7 & 21.5 & 16.9 & 77.9 \\
\hline 1938-1942 & 560 & 8.0 & 17.8 & 15.9 & 75.1 \\
\hline $1933-1937$ & 727 & 7.7 & 16.6 & 14.5 & 68.7 \\
\hline Total & 2,037 & 8.2 & 19.1 & 16.1 & 75.1 \\
\hline
\end{tabular}

${ }^{a}$ Mean number of recalled words (out of 10).

${ }^{b}$ Mean number of animals named within 1 min.

${ }^{c}$ Mean number of correctly crossed out letters.

${ }^{d}$ Mean score of activities of daily living. years. The proportion of subjects with university education was higher in Russia, consistent with previous studies and routine statistics, and in both countries it was higher in men than in women. The mean number of household items owned by participants was similar in the 2 countries, but Russians reported higher levels of subjectively perceived material deprivation. The mean annual alcohol intake was slightly higher in Czechs than in Novosibirsk, but Russian men reported a substantially higher prevalence of binge drinking. The crude means of all 3 cognitive outcomes were lower in Novosibirsk than in the Czech towns; physical functions were similar in
Czech and Russian men, but were lower in Russian women.

Table 2 shows the means of cognitive and physical functions by year of birth. It is apparent that, with exception of letter search in men, the means of all outcomes are similar in the youngest group, but are much lower in Novosibirsk than in Czech towns in the older age groups. In other words, the gradient by year of birth was steeper in Russia than in the Czech Republic.

The fitted mean cognitive and physical functions by year of birth (based on linear regression), shown in figures 1 (men) and 2 (women), confirm this pattern. Even where younger Russian participants showed better health than Czechs born in the same period (as for physical functioning in men), their older counterparts had poorer health than older Czechs.

The multivariate models of the birth year gradients in the 2 countries are shown in table 3 . In both sexes, the unadjusted gradient was considerably steeper in Novosibirsk than in the Czech towns for all 4 outcomes, except for letter search in men (where Russians had lower scores across all ages). For cognitive outcomes, adjustment for covariates attenuated the year of birth gradient, but did not affect the differences in the slope with birth year between countries; there was no consistent pattern with regard to the relative proportion of the slopes explained by SES and health for the cognitive outcomes, with health sometimes appearing to exert a suppressor effect. For physical functioning, as expected, the health indicators had a stronger attenuating effect than cognitive functions; adjustment for both socioeconomic and health indicators reduced the differences between the 2 countries in the birth year gradient in men.

In additional analyses, we found that results on delayed word recall (not shown in table) exhibited a pattern virtually identical to that reported here (not shown in table). Place of birth (Novosibirsk region vs. elsewhere in Russia), leg length (used an indicator of childhood conditions), and measures of longer alcohol intake (drinking frequency and annual intake) and drinking pattern (binge drinking and the mean dose per drinking session) had no or minimal effects on cognitive functions once socioeconomic factors and biological covariates were controlled for; these factors therefore did not make a contribution to explaining the differences in levels and slopes by birth year in cognitive functions (not shown in table). 

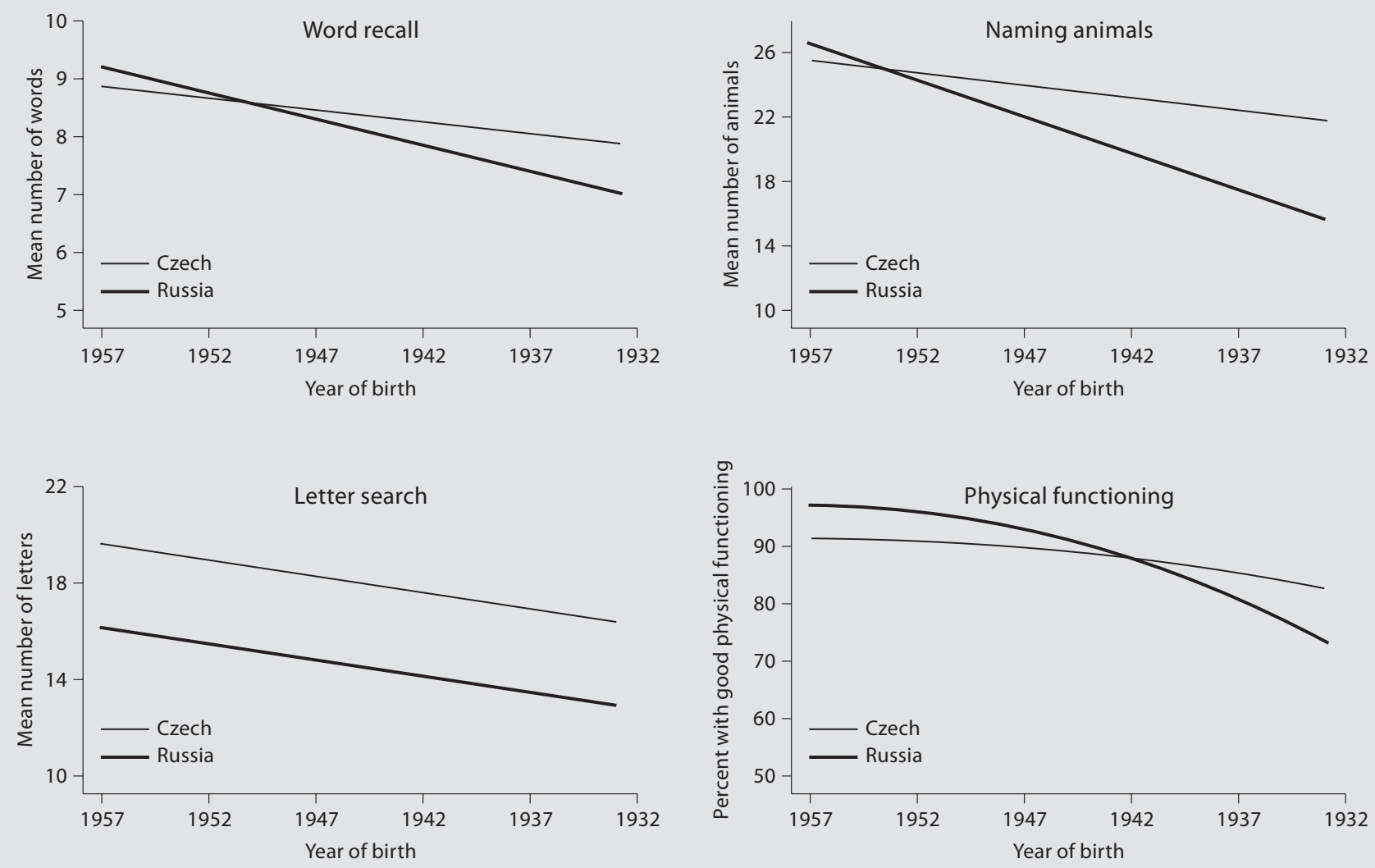

Fig. 1. Cognitive and physical functions by year of birth (reversed scale) and country in men (fitted lines), not adjusted for covariates.

\section{Discussion}

To our knowledge, this is the first population-based study to assess cognitive function in Russia and one of the first, and certainly the largest to date, in the eastern European region. Except letter search in men, we found a steeper gradient by year of birth in all measures of cognitive function in Russians than among Czechs, which was not fully explained by socioeconomic indicators or health. Consistently with previous studies, we also found a similar birth year effect differential, i.e. a steeper one in Russia, in physical performance.

Although, for simplicity, we refer to countries, our study populations were based in 1 city in Russia and in 6 towns in the Czech Republic. Although these urban populations are very similar to the national figures in terms of levels and trends in mortality, socioeconomic indicators and health behaviours, the study did not examine nationally representative samples and extrapolation to whole countries needs caution.

The strengths of this study include: the large samples based on representative population-based sampling frames in both countries; the use of psychometric cognitive test scores rather than ascertainment of cognitive impairment from clinical records, as previously undertaken by Suhanov et al. [14] in Russia; and the cross-national standardization and harmonization of the data collection protocol.

The major limitation of this study, however, is its crosssectional design, which makes it impossible to separate inter-individual decline with age from selective survival bias and period and cohort effects, which may all affect cognitive functioning.

The survival bias would probably operate in the opposite direction, i.e. the healthier (who are probably those with better cognitive functions) are more likely to survive 

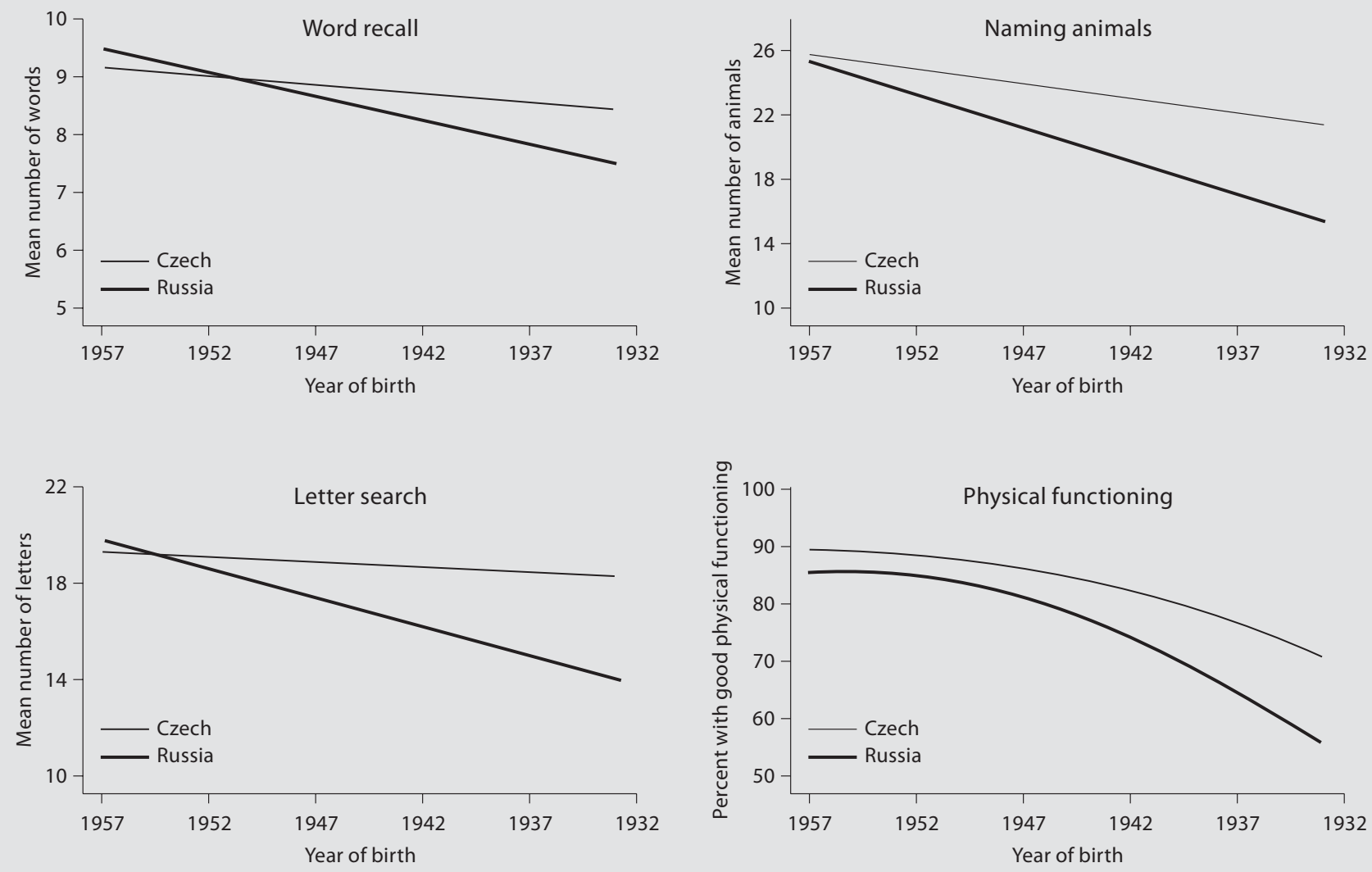

Fig. 2. Cognitive and physical functions by year of birth (reversed scale) and country in women (fitted lines), not adjusted for covariates.

and to be included in the study; this would tend to overestimate the levels of cognitive and physical functions in both cohorts, but more so in Russia, whose social history throughout the 20th century has been far more difficult than that of the Czech Republic. The question of whether the steep gradient in cognitive and physical function by year of birth reflects recent exposures or a cohort effect is more difficult to settle.

However, this important issue may also point towards the most likely explanation for the steeper birth year gradient in cognitive and physical function in Russians compared to Czechs: an accumulation of disadvantage over the life course. The older Russians in this study lived through far more difficult historical times, including major deprivations during World War II, than their younger compatriots, and this experience may have differentially affected their health, including cognitive function, in comparison to those of similar age in the former Czechoslovakia. The following figures illustrate the historical differences between the 2 countries. Between the wars, the Czech Republic, the more affluent part of the former Czechoslovakia, was among the most developed countries; in 1935, infant mortality was 105 per 1,000 live births and life expectancy at birth (for men and women combined) was 57.9 years, and the country remained prosperous until 1948. Russia, as part of the former Soviet Union, on the other hand, struggled both before and after World War II; in 1935 (not a year of famine), infant mortality was 198 per 1,000 live births and life expectancy at birth was 39.6 years (men and women combined) [15]. These differences between the countries largely persisted after World War II, until they diverged further during the societal transformation in the 1990s $[1,16]$.

Yet it is difficult to isolate any particular phase of the life course in which this adversity may have exerted its 
Table 3. Linear regression intercepts and coefficients for cognitive functions by 10 -year decrease in year of birth in the Czech Republic and Russia

\begin{tabular}{|c|c|c|c|c|c|c|}
\hline & \multirow[t]{2}{*}{ Model } & \multicolumn{2}{|l|}{ Intercept } & \multicolumn{3}{|c|}{ Slope with age } \\
\hline & & Czech Rep. & Russia & Czech Rep. & Russia & $\begin{array}{l}\mathrm{p} \text { (interaction } \\
\text { age vs. country) }\end{array}$ \\
\hline $\begin{array}{l}\text { Men } \\
\text { Immediate word recall }\end{array}$ & $\begin{array}{l}\text { year of birth only } \\
+ \text { SES } \\
\text { full model }^{\mathrm{b}}\end{array}$ & $\begin{array}{l}8.8(0.1) \\
- \\
-\end{array}$ & $\begin{array}{l}9.2(0.1) \\
- \\
-\end{array}$ & $\begin{array}{l}-0.40(0.06) \\
-0.42(0.05) \\
-0.31(0.06)\end{array}$ & $\begin{array}{l}-0.92(0.06) \\
-0.78(0.06) \\
-0.63(0.07)\end{array}$ & $\begin{array}{l}<0.001 \\
<0.001 \\
<0.001\end{array}$ \\
\hline Animals & $\begin{array}{l}\text { year of birth only } \\
+ \text { SES }^{\mathrm{a}} \\
\text { full model }^{\mathrm{b}}\end{array}$ & $\begin{array}{l}25.6(0.5) \\
- \\
-\end{array}$ & $\begin{array}{l}26.5(0.4) \\
- \\
-\end{array}$ & $\begin{array}{l}-1.56(0.28) \\
-1.65(0.26) \\
-1.17(0.28)\end{array}$ & $\begin{array}{l}-4.47(0.22) \\
-3.67(0.23) \\
-3.18(0.24)\end{array}$ & $\begin{array}{l}<0.001 \\
<0.001 \\
<0.001\end{array}$ \\
\hline Letter crossing & $\begin{array}{l}\text { year of birth only } \\
+ \text { SES } \\
\text { full model }^{\mathrm{b}}\end{array}$ & $\begin{array}{l}19.6(0.6) \\
- \\
-\end{array}$ & $\begin{array}{l}16.3(0.4) \\
- \\
-\end{array}$ & $\begin{array}{l}-1.29(0.37) \\
-1.31(0.33) \\
-1.31(0.36)\end{array}$ & $\begin{array}{l}-1.34(0.25) \\
-0.85(0.23) \\
-1.32(0.26)\end{array}$ & $\begin{array}{l}0.908 \\
0.290 \\
0.974\end{array}$ \\
\hline Physical functions, \% of max. & $\begin{array}{l}\text { year of birth only } \\
+ \text { SES } \\
\text { full model }^{\mathrm{b}}\end{array}$ & $\begin{array}{l}94.3(2.4) \\
- \\
-\end{array}$ & $\begin{array}{l}101.8(2.0) \\
- \\
-\end{array}$ & $\begin{array}{l}-4.5(1.4) \\
-5.1(1.4) \\
-1.4(1.4)\end{array}$ & $\begin{array}{r}-10.5(1.2) \\
-7.0(1.3) \\
-3.2(1.3)\end{array}$ & $\begin{array}{l}0.001 \\
0.289 \\
0.333\end{array}$ \\
\hline $\begin{array}{l}\text { Women } \\
\text { Immediate word recall }\end{array}$ & $\begin{array}{l}\text { year of birth only } \\
+ \text { SES }^{\mathrm{a}} \\
\text { full model }^{\mathrm{b}}\end{array}$ & $\begin{array}{l}9.2(0.1) \\
- \\
-\end{array}$ & $\begin{array}{l}9.5(0.1) \\
- \\
-\end{array}$ & $\begin{array}{l}-0.31(0.05) \\
-0.23(0.04) \\
-0.11(0.05)\end{array}$ & $\begin{array}{l}-0.82(0.05) \\
-0.67(0.05) \\
-0.52(0.06)\end{array}$ & $\begin{array}{l}<0.001 \\
<0.001 \\
<0.001\end{array}$ \\
\hline Animals & $\begin{array}{l}\text { year of birth only } \\
+ \text { SES } \\
\text { full model }^{\mathrm{b}}\end{array}$ & $\begin{array}{l}26.0(0.4) \\
- \\
-\end{array}$ & $\begin{array}{l}25.6(0.3) \\
- \\
-\end{array}$ & $\begin{array}{l}-1.82(0.23) \\
-1.30(0.21) \\
-0.88(0.23)\end{array}$ & $\begin{array}{l}-4.15(0.19) \\
-3.24(0.19) \\
-2.97(0.21)\end{array}$ & $\begin{array}{l}<0.001 \\
<0.001 \\
<0.001\end{array}$ \\
\hline Letter crossing & $\begin{array}{l}\text { year of birth only } \\
+ \text { SES }^{\mathrm{a}} \\
\text { full model }^{\mathrm{b}}\end{array}$ & $\begin{array}{l}19.3(0.5) \\
- \\
-\end{array}$ & $\begin{array}{l}19.7(0.4) \\
- \\
-\end{array}$ & $\begin{array}{r}-0.42(0.30) \\
-0.15(0.28) \\
0.17(0.31)\end{array}$ & $\begin{array}{l}-2.33(0.23) \\
-1.81(0.21) \\
-2.12(0.26)\end{array}$ & $\begin{array}{l}<0.001 \\
<0.001 \\
<0.001\end{array}$ \\
\hline Physical functions, $\%$ of max. & $\begin{array}{l}\text { year of birth only } \\
+ \text { SES }^{\mathrm{a}} \\
\text { full model }^{\mathrm{b}}\end{array}$ & $\begin{array}{l}93.3(2.4) \\
- \\
-\end{array}$ & $\begin{array}{l}93.0(2.5) \\
- \\
-\end{array}$ & $\begin{array}{l}-8.3(1.4) \\
-7.1(1.5) \\
-2.6(1.6)\end{array}$ & $\begin{array}{r}-14.3(1.5) \\
-10.2(1.6) \\
-8.3(1.7)\end{array}$ & $\begin{array}{l}0.004 \\
0.135 \\
0.007\end{array}$ \\
\hline
\end{tabular}

Figures in parentheses are SE.

a Adjusted for education and deprivation.

b Adjusted for education, deprivation, systolic blood pressure, smoking, body mass index, leg length, FEV , annual alcohol consumption and binge drinking in the last 12 months.

greatest effect. For example, while we have previously reported that persons who lived through World War II had shorter stature than would be expected on the basis of long-term secular trends [17], the steeper birth year gradient in Russians in this study was not explained by leg length, which can serve as a biomarker of early adversity [18].

It may be that cumulative adversity over the life course, beginning with poor material conditions in the 1930s, through World War II and its aftermath, eventually leading to job insecurities and social changes in the immedi- ate post-Soviet era, have had a long-term 'weathering' effect on health, particularly in older Russians. In fact, the weathering hypothesis was proposed to account for the early health deterioration in African-Americans - essentially a process of accelerated aging - as a consequence of just such a cumulative impact of repeated adversity [19]. The biological basis of this process has been conceptualized in terms of 'allostatic load' [20], or wear and tear from repeated physiological adaptation to stressors. However, as noted in the 'Introduction', there are a wide range of material, behavioural and psychosocial factors that 
mediate the association between disadvantage and cognitive function.

Importantly, our finding of a differential gradient by year of birth between populations is consistent with findings from within population studies in the west. These studies have shown steeper age gradients in physical and cognitive function in socioeconomically disadvantaged groups [6]. In the west, the faster age-related cognitive decline associated with social disadvantage is driven more by low educational attainment than by achieved social position $[21,22]$. Indeed, education also plays an important role in the onset of functional limitations and chronic conditions [23], and low educational attainment is strongly associated with the clinical expression of Alzheimer's disease [24], a major individual and societal burden in later life. This does not mean, however, that education is necessarily the universal driving force of functional decline across different societies. While Russians have relatively high levels of education, they have experienced pronounced and long-term disadvantage in many other aspects of SES over their life course, which is likely to have contributed to their cognitive levels at older ages.

These findings have practical implications. In a systematic review of 19 longitudinal studies, Bruscoli and
Lovestone [25] found that cognitive test performance was a strong predictor of dementia incidence, although there are factors that can protect this performance, with strong implications for intervention, such as adult education and training [26] and physical exercise [27]. To our knowledge, there are no published or ongoing population-based studies designed to estimate the prevalence of Alzheimer's disease and other forms of dementia in Russia. Given the steep gradient in cognitive functions by year of birth found in this study, and given the cost of Alzheimer's disease in the west $[28,29]$, long-term follow-up of the HAPIEE cohorts and other studies of population rates of cognitive impairment in Russia should be a priority.

\section{Acknowledgment}

The authors would like to thank the local Public Health Institutes participating in the Czech study for collaboration in collecting the data. The study was funded by grants from the Wellcome Trust, the MacArthur Foundation Initiative on Social Upheaval and Health, and by the US National Institute of Ageing. The role of the sponsors was limited to the funding of the study as proposed.

\section{References}

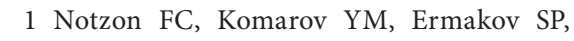
Sempos CT, Marks JS, Sempos EV: Causes of declining life expectancy in Russia. JAMA 1998;279:793-800.

$\checkmark 2$ Leon DA, Chenet L, Shkolnikov V, Zakharov S, Shapiro J, Rakhmanova G, Vassin S, McKee M: Huge variation in Russian mortality rates 1984-94: artefact, alcohol, or what? Lancet 1997;350:383-388.

3 Shkolnikov VM, Mesle F, Vallin J: Recent trends in life expectancy and causes of death in Russia, 1970-1993; in Bobadilla JL, Costello CA, Mitchell F (eds): Premature Death in the New Independent States. Washington, National Academy Press, 1997, pp 34-65.

4 Andreev EM, McKee M, Shkolnikov VM: Health expectancy in the Russian Federation: a new perspective on the health divide in Europe. Bull WHO 2003;81:778-787.

5 Bobak M, Kristenson M, Pikhart H, Marmot M: Life span and disability: a cross-sectional comparison of Russian and Swedish community based data. BMJ 2004;329:767.

6 Chandola T, Ferrie JE, Sacker A, Marmot M: Social inequalities in self reported health in early old age: follow-up of prospective cohort study. BMJ 2007;334:990.
Geronimus AT, Bound J, Keene D, Hicken M: Black-white differences in age trajectories of hypertension prevalence among adult women and men, 1999-2002. Ethn Dis 2007;17: $40-48$.

8 Turrell G, Lynch JW, Kaplan GA, Everson SA, Helkala EL, Kauhanen J, Salonen JT: Socioeconomic position across the lifecourse and cognitive function in late middle age. J Gerontol B Psychol Sci Soc Sci 2002;57:S43S51.

-9 Singh-Manoux A, Richards M, Marmot M: Socioeconomic position across the lifecourse: how does it relate to cognitive function in mid-life? Ann Epidemiol 2005; 15: 572-578.

10 Bobak M, Room R, Kubinova R, Malyutina S, Pajak A, Kurilovitch S, Pikhart H, ToporMadry R, Nikitin Y, Marmot M: Contribution of alcohol consumption and drinking patterns to rates of alcohol-related problems in urban populations in Russia, Poland and the Czech Republic: a cross-sectional study. J Epidemiol Comm Health 2004;58:238242 .
1 Peasey A, Bobak M, Kubinova R, Malyutina S, Pajak A, Tamosiunas A, Pikhart H, Nicholson A, Marmot M: Determinants of cardiovascular disease and other non-communicable diseases in Central and Eastern Europe: rationale and design of the HAPIEE study. BMC Public Health 2006;6:255

12 Ware JE, Sherbourne CD: The MOS 36-Item Short-Form Health Survey (SF-36). I. Conceptual framework and item selection. Med Care 1992;30:473-483.

13 McHorney CA, Ware JE, Raczek AE: The MOS 36-Item Short-Form Health Survey (SF-36): II. Psychometric and clinical tests of validity in measuring physical and mental health constructs. Med Care 1993;31:247263.

14 Suhanov AV, Pilipenko PI, Korczyn AD, Hofman A, Voevoda MI, Shishkin SV, Simonova GI, Nikitin YP, Feigin VL: Risk factors for Alzheimer's disease in Russia: a casecontrol study. Eur J Neurol 2006; 13: 990-995.

15 Haynes M, Husan R: A century of state murder? Death and policy in twentieth-century Russia. London, Pluto Press, 2003. 
16 United Nations Children's Fund: A decade of transition. Regional Monitoring Report No. 8. Florence, UNICEF, 2001.

17 Webb EA, Kuh D, Peasey A, Pajak A, Malyutina S, Kubinova R, Topor-Madry R, Denisova $D$, Capkova $N$, Marmot $M$, Bobak $M$ : Childhood socioeconomic circumstances and adult height and leg length in Central and Eastern Europe. J Epidemiol Community Health 2008;62:351-357.

$>18$ Li L, Dangour AD, Power C: Early life influences on adult leg and trunk length in the 1958 British birth cohort. Am J Hum Biol 2007; 19:836-843.

-19 Geronimus AT, Hicken M, Keene D, Bound J: 'Weathering' and age patterns of allostatic load scores among blacks and whites in the United States. Am J Public Health 2006;96: 826-833.

20 McEwen BS: Protective and damaging effects of stress mediators. N Engl J Med 1998; 338:171-179.
1 Lee S, Kawachi I, Berkman LF, Grodstein F Education, other socioeconomic indicators, and cognitive function. Am J Epidemiol 2003;157:712-720

22 Richards M, Shipley B, Fuhrer R, Wadsworth ME: Cognitive ability in childhood and cognitive decline in mid-life: longitudinal birth cohort study. BMJ 2004;328:552.

23 Herd P, Goesling B, House JS: Socioeconomic position and health: the differential effects of education versus income on the onset versus progression of health problems. J Health Soc Behav 2007;48:223-238.

24 Richards M, Deary IJ: A life course approach to cognitive reserve: a model for cognitive aging and development? Ann Neurol 2005; 58:617-622.
25 Bruscoli M, Lovestone S: Is MCI really just early dementia? A systematic review of conversion studies. Int Psychogeriatr 2004;16: 129-140.

26 Hatch SL, Feinstein L, Link B, Wadsworth MEJ, Richards M: The continuing benefits of education: adult education and midlife cognitive ability in the British 1946 birth cohort. J Gerontol 2007;62:S404-S414.

27 Kramer AF, Erickson KL: Capitalizing on cortical plasticity: influence of physical activity on cognition and brain function. Trends Cogn Sci 2007;11:342-348.

28 Gray A, Fenn P: The cost of Alzheimer's disease in England. Alzheimers Rev 1994;4:8184.

29 Lowin A, Knapp M, McCrone P: Alzheimer's disease in the UK: comparative evidence on cost of illness and volume of health services research funding. Int J Geriatr Psychiatry 2001;16:1143-1148. 